Monatsschrift f. Geburtshülfe u. Gynäkologie 1933;94:I-IV

\title{
Contents, Vol. 94, 1933
}

Inhaltsverzeichnis.

Originalarbeiten. Seit $\beta$

Alexander, Leo, Zusammentreffen von Mißgeburten und mangel-

hafter kindlicher Konstitution mit Albuminurie bei den Müttern (a).

Liegt in den Nieren die Schwellenwertsgrenze für den spontanen

Wehenbeginn? (b). . 141

Chanina-Graiduk, F., Uber eine ausgetragene Tubengravidität mit

Erhalten einer lebenden Frucht

Deinhardt, Dietrich, Evipan-Natrium, ein neues intravenöses Kurz-

und Basis-Narkotikum 52

Dienz, H., Beitrag zur Kritik der Avertiatodesfälle 227

Ehrhardt, Karl, und Konrad Kiihn, Eine bisher unbekannte bio-

logische Wirkung des weiblichen Sexualhormons. (Künstliches Wachs-

tum der Legeröhre bei Bitterlingen.) 1

Franqué, Otto von, Zur Erkennung und Bekämpfung des Karzinoms 254 Fuge, K., Uber einen

Fall von günstig verlaufener Hirnembolie als

Folge eines kriminellen Abortes 273

Gocke, Hans, Uber Blutungen im Wochenbett

G-ohlisch, Ingeborg, Mensueller Zyklus und Lipoidgehalt der Uterus-

schleimhaut 223

Guthmann, Heinrich, und L. Heß, Über den Einfluß von Moor-

bädern auf den Blutdruck 55

Haupt, W., Darf der Drüsenkrebs des Gebärmutterhalses für strahlen-

refraktär angesehen werden? 364

Heseler, Otto, Zur Difierentialdiagnose der Unterleibsbrûche und

Tumoren in Bruchgegenden 277

Heß, L., siehe Gruthmann, Heinrich.

Hinrichs, Ferdinand, Über Scheidenverletzungen 240

Kühn, Konrad, siehe Ehrhardt, Karl.

Jacobi, Hans, und J. Lindner, Indikationen, Erfolge und Versager

der Rõntgenkastration 178

Lange, Konrad, Zum spontanen Lagewechsel des Kindes am Ende

der normalen Schwangerschaft 147

Liebmann, Stephan, Über die Ursachen cler Neugeborenenmortalität 338

Lindner, J., siehe Jacobi, Hans.

Mosettig, Eg on, Zur Kasuistik und Problematik der Pfählungs-

verletzungen 357

Osiakina, A. I., und K. D. Schmatok, Über die Dezidualreaktion der

Tube bei intrauteriner und Tubenschwangerschaft und ihre Bedeutung 
für die Ätiologie der letzteren 329

Rosenblatt, J., Über den Wert der Hypophysinprobe zur Diagnose

der ausgetragenen bzw. übertragenen Schwangerschaft. Bemerkungen

zu der Arbeit von Dr. Egon Werner Winter 40

Rosenstein, Walter, Die vaginale Uterusexstirpation sub partu . . 282 Salacz, Paul v., Uterus

duplex mit gleichzeitiger Schwangerschaft

in beiden Uterushälften 321

Schmatok, K. D., siehe Osiakina, A. I.

Schott, Paul, Über zystische Myome des Uterus 45

Seitz, L., Über eugenische Sterilisierung und eugenische Schwanger-

schaftsunterbrechung 129

- $\quad$ Weitere Bemerkungen und Vorschläge zum eugenischen Sterilisierungs-

gesetzentwurf 209

- Spontanamputationen durch amniotische Fäden können mit primärer

Minderwertigkeit der Fruchtanlage zusammenhängen 236

$\mathrm{XY}$ Inhaltsverzeichøis.

Seit $\theta$

Stark, Elisabeth, Die Therapie der Pyelitis, mit besonderer Berück-

sichtigung der Nierenbeckenspülung und des Dauerkatheterismus

der Ureteren 29

Winter, Egon Werner, Über den Wert der Hypophysinprobe zur

Diagnose der ausgetragenen Scbrwangerschaft. Erwiderung auf die

Bemerkungen von J. Eosenblatt 43

Über die Allgemeinbehandlung beim Fluor vaginalis $\quad 166$

Die Bedeutung der sechsmomentigen Mikrosedimentierung der Erythro-

zyten für die Gynäkologie im Vergleich zur Makrosedimentierung

nach Linzenmeier 245

Wirz, Paul, Trübungsmessungen im Serum und in Serumgemischen.

Ein Beitrag zur Frage der Individualität des Blutes und der Mutter-

Kind-Beziehungen 5

Victor Albeck $\dagger \quad 319$

Grenzgebiete der Geburtshilfe und Gynäkologie.

Stoffwechselforschungen bei Schwangeren (III). Jahresübersicht von Privatdozent Dr. A. Bock, Berlin 65

Physikalische Heilmethode $\pi$ einschließlich der Hydrotherapie. Von Her man Franken, Freiburg i. Br 189

Lebererkrankungen, uropoetisches System und Nierenerkrankungen in ihren

Beziehungen zur Geburtshilfe und Gynäkologie. $\lambda \Gamma$ ou Privatdozent

Dr. Hans Rupp, Bonn a. Eh 289

Kreislaufforschung des vergangenen Jahres. Von Privatdozent Dr. A.

Pfleiderer, Tubingen 368

Sitzungsberichte aus geburtshilflich-gynäkologischen Gesellschaften.

Gynäkologische Gesellschaft zu Breslau. Sitzung vom 24. Januar 193277

- $\quad$ Sitzung vom 21. Februar $1933 \quad 301$

Gesellschaft für Geburtshilfe und Gynäkologie zu Berlin. Sitzungen vom

28. Oktober und 11. November 1932 
Sitzung vom 25. November 1932

Münchener Gynäkologische Gesellschaft. Sitzungen vom 28. April, 23. Juni und 21. Juli 1932 ... 93

Mittelrheinische Gesellschaft für Geburtshilfe und Gynäkologie. 89. Sitzung anläßlich der 92. Naturforschertagung in Wiesbaden. (Gemeínsam mit der Oberrheinischen, Niederrheinischen und Bayrischen Gesellschaft für Gynäkologie und Geburtshilfe.) Wiesbaden, 24. und 25. Sep tember 1932105

Nordwestdeutsche Gesellschaft für Gynäkologie. Sitzung vom 29. Oktober 1932 in Hamburg 194

Geburtshilflich- gynäkologische Gesellschaft in Wien. Sitzungen vom 13. Dezember, 20. Dezember 1932, 10. Januar und 14. Februar 1933201

- $\quad$ Sitzung vom 14. März 1933314

Buchbesprechungen 208, 316, 393

Personalien 128, 208, 320, 396 